\title{
Address urban regeneration challenge with temporary creative uses: the case of Beijing's Dashilar area
}

Document Version

Accepted author manuscript

Link to publication record in Manchester Research Explorer

\section{Citation for published version (APA):}

Zhang, A. (2020). Address urban regeneration challenge with temporary creative uses: the case of Beijing's Dashilar area. In L. Andres, \& A. Zhang (Eds.), Transforming Cities through Temporary Urbanism: A Comparative International Overview Springer Nature.

\section{Published in:}

Transforming Cities through Temporary Urbanism

\section{Citing this paper}

Please note that where the full-text provided on Manchester Research Explorer is the Author Accepted Manuscript or Proof version this may differ from the final Published version. If citing, it is advised that you check and use the publisher's definitive version.

\section{General rights}

Copyright and moral rights for the publications made accessible in the Research Explorer are retained by the authors and/or other copyright owners and it is a condition of accessing publications that users recognise and abide by the legal requirements associated with these rights.

\section{Takedown policy}

If you believe that this document breaches copyright please refer to the University of Manchester's Takedown Procedures [http://man.ac.uk/04Y6Bo] or contact uml.scholarlycommunications@manchester.ac.uk providing relevant details, so we can investigate your claim.

\section{OPEN ACCESS}




\section{Chapter 13}

\section{Address urban regeneration challenge with temporary creative uses: the case of Beijing's Dashilar area}

\section{Amy Y. Zhang}

\section{Introduction}

In recent years, temporary and pop-up uses of vacant urban spaces as artistic or cultural sites, which were previously often regarded as 'marginal', have become more popular among city planners and policy makers. Such temporary urbanism practices have been increasingly enlisted in creative city strategies to create urban landscape that attracts 'creative class' consumers to eventually achieve urban regeneration and revalorisation, particularly in the West (Andres 2013; Colomb 2012; Ferreri 2015; Harris 2015; O'Callaghan and Lawtown 2015; Schaller and Guinand 2018). Existing studies identify that temporary and pop-up creative uses are valued by city governments in the West for two main reasons. Firstly, the prior illegitimate status of the uses grants them an edgy novelty appealing to the creative class consumers. Secondly, such uses have the ability to induce spatial-temporal imagination and alter perceptions of places by providing a materialised potential look and feel to vacant urban spaces at a relatively low cost and flexibility in an era of austerity after the financial crisis of 2008 (Andres 2013; Colomb 2012; Harris 2015). It is argued that through temporary and popup uses, presently run-down, vacant, or 'wasted' areas can be imagined "as playgrounds or workspaces for 'creative' entrepreneurs; as milieux that can attract other creative workers and consumers ... or as tourist attractions" (Colomb, 2012, p. 138) in the future, and thus may gain the interests of investors and developers (Andres 2013; Colomb 2012; Harris 2015; Schaller and Guinand 2018).

There has, so far, been relatively limited research on the reasons for and application of temporary and pop-up creative uses in urban regeneration by city governments in nonWestern and/or Global South contexts. Given that the choice of employing temporary/popup creative uses for urban regeneration in Western cities is usually situated in specific political-economic contexts - austerity and financial crisis - and that the effects of using culture and art for urban regeneration are shaped by socio-cultural dynamics, it is necessary to contextualise the choice and use of such urban strategies when they are implemented in non-Western and/or Global South situations. In this chapter, I discuss a case of temporary creative uses being adopted for urban regeneration in Beijing, China to reflect on the potential diversity of temporary urbanism practices, even within those that are engaged by city governments for regeneration purposes. Data for this chapter is collected from interviews with staff members who are in charge of the execution and public relations of the regeneration project in the case study (Dashilar area in Beijing) and from relevant policy and planning documents and the official website of Dashilar (http://dashilar.beijing99.cn).

\section{Dashilar area and its regeneration challenge}


Zhang, A.Y. 2021. Address urban regeneration challenge with temporary creative uses: the case of Beijing's Dashilar area. In Andres, L., and Zhang, A.Y. (eds.) Transforming Cities through Temporary Urbanism: A Comparative International Overview. Springer.

The case examined here is an urban regeneration project in one of Beijing's inner-city historical conservation areas: Dashilar. The Dashilar area is located in the centre of Beijing, south of the Forbidden City and Tiananmen Square and near Qianmen, and jurisdictionally in the Xicheng District. This area is famous for its main commercial street, which was built in the Ming Dynasty (1368-1644) and now serves as a major tourist attraction. Hutongs (small alleys) in the area are mostly in a mix of residential and commercial uses. Like many other older neighbourhoods in the inner city of Beijing, Dashilar is densely populated with most of its residents living in low-rise and historic courtyard houses. Many of these courtyard houses face the problems of overcrowding, poor maintenance, and unauthorised additions to the original buildings, and need to be renovated and/or restored.

From the 1990s to the early 2000s, urban regeneration in Beijing's inner-city areas was carried out mostly through a property-led redevelopment mode (He and Wu 2005) and consisted of large-scale demolition of housing and displacement of local residents, few of whom could afford to move back to the areas after redevelopment and into the newly built commercial apartment buildings (Shin 2009). Unsurprisingly, this mode of urban regeneration caused a series of problems: forceful displacement led to strong social discontent and resistance while large-scale demolition and redevelopment completely "uprooted Old Beijing's culture" (interview with regeneration project staff, S-1). This redevelopment mode slowed down after Beijing Municipal Government adopted planning policies for urban conservation. It issued the 'Plan for Conservation and Control Scope for the Historic and Cultural Conservation Areas in Beijing Old City' in 1999, which designated 25 areas as historic and cultural conservation areas (BMG 1999), and 'Conservation Planning for the 25 Historic and Cultural Conservation Areas in Beijing Old City' in 2002 (BMCPNR 2002a).

The Dashilar area was named among the 25 conservation areas and was then subject to a series of requirements as well as constraints on its regeneration, as set out by Beijing Municipal Government's planning policies for urban conservation. First, both of the plans issued in 1999 and 2002 emphasised the need for incremental renovation and improvement instead of large-scale demolition and reconstruction in designated conservation areas. The conservation planning issued in 2002 particularly named 'micro-circulation' as the new mode of urban regeneration, meaning residents need to voluntarily apply to relocate and the courtyard has to be the basic unit for renovation and restoration with the overall structure of the courtyard maintained (BMCPNR 2002a, 2002b). ${ }^{1}$ Secondly, regeneration and conservation in the conservation areas are required to ensure the 'authenticity' of these areas, through either preserving or restoring the historical features of the built environment, where the size, form, and colour of renovated properties need to be in accordance with the overall aesthetic of the conservation areas. And any properties or decorations that do not fit this requirement need to be demolished or taken down (BMCPNR 2002a; BMG 1999). Thirdly, reducing population density, namely displacing existing residents, has been a key focus of the

\footnotetext{
${ }^{1}$ Shin (2010) in his study of urban conservation and revalorisation in the case of Nanluoguxiang in Beijing provided a detailed account of how the 'micro-circulation' mode is carried out: "This approach requires all registered residents in the courtyard to sign a collective application for courtyard restoration, and they would also have to agree on a relocation plan, which usually involves their permanent displacement upon receiving compensation ... allows courtyard houses to be emptied and released for restoration by corporate and individual investors" (Shin 2010, S49-S50).
} 
Zhang, A.Y. 2021. Address urban regeneration challenge with temporary creative uses: the case of Beijing's Dashilar area. In Andres, L., and Zhang, A.Y. (eds.) Transforming Cities through Temporary Urbanism: A Comparative International Overview. Springer.

plans and policies for the conservation areas since the beginning. In the conservation planning issued in 2002, the target was set to reduce the total number of residents in the conservation areas from 167,000 to 118,000 , displacing $41 \%$ of the total population (BMCPNR 2002a).

The district government thus faces a series of challenges in carrying out regeneration in the Dashilar area. On the one hand, the requirement that regeneration in designated conservation areas needs to be incremental and based on residents' voluntary relocation makes meeting the target of reducing population density difficult. And on the other hand, the cost of resorting and renovating housing and the overall built environment, combined with that of improving infrastructure in the area and compensating residents who are displaced, places a relatively high financial burden on the district government, which the municipal government has even recognised (BMCPNR 2011). While regeneration can potentially generate income for the district government, who can lease the land (and properties on it) at a higher price to investors, the restriction introduced by the 'micro-circulation' approach on the scale and speed of urban regeneration in the Dashilar area makes it difficult for the district government to attract one main investor and thus use regeneration as an effective tool for generating income (interviews with regeneration project staff, S-1 and S-2).

\section{Temporary creative uses as the strategy}

To address the challenges posed by the restrictions on regeneration in the Dashilar area, temporary creative uses came into the picture. Temporary creative uses were introduced to the Dashilar area through its involvement in Beijing Design Week, which was initiated in 2011 to strengthen Beijing's application to UNESCO's Creative Cities Network as a 'City of Design' (interview with regeneration project staff, S-3). Beijing was awarded the title of 'City of Design' in 2012 and Beijing Design Week became a key component of this title and its flagship event. As the name suggests, Beijing Design Week is a week-long event and is usually scheduled at the end of September and the beginning of October, overlapping with the start of the 'Golden Week' of the National Day holiday to maximise the number of audiences it can draw. It contains multiple components such as a design fair, exhibitions, public forums, workshops, fashion shows, an award ceremony, and a showcase of a guest city (London was the first guest city in 2011 and Helsinki is selected to be the guest city for 2020). These components are spread out and take place at multiple locations across the city, including the Dashilar area, where vacant courtyard houses are turned into spaces for design exhibitions and shops.

The temporary nature of Beijing Design Week as a week-long event thus introduces temporary creative uses into the Dashilar area. Since 2011, artists, designers, and other individuals and enterprises in cultural and creative sectors would be invited to open up temporary exhibitions and shops in vacant courtyard houses in the Dashilar area during Beijing Design Week (Figure 1). These were at first concentrated in one alley (Yangmeizhu xiejie) and gradually expanded to another two alleys. Since 2013, architects, planners, and academics are also invited to propose and conduct pilot projects in the area during Beijing Design Week. These involve beautifying the alleys, renovating courtyard houses (see Figure 2 for an example), and turning vacant courtyard houses into alternative uses, such as hostels or Airbnbs, especially those not in optimum locations for commercial uses. And in 2016, the Dashilar Bazaar was introduced in the summer to expand the presence of temporary creative 
Zhang, A.Y. 2021. Address urban regeneration challenge with temporary creative uses: the case of Beijing's Dashilar area. In Andres, L., and Zhang, A.Y. (eds.) Transforming Cities through Temporary Urbanism: A Comparative International Overview. Springer.

uses beyond the period of Beijing Design Week, partly due to the notable differences in the area between Beijing Design Week and other times (see Figure 3).

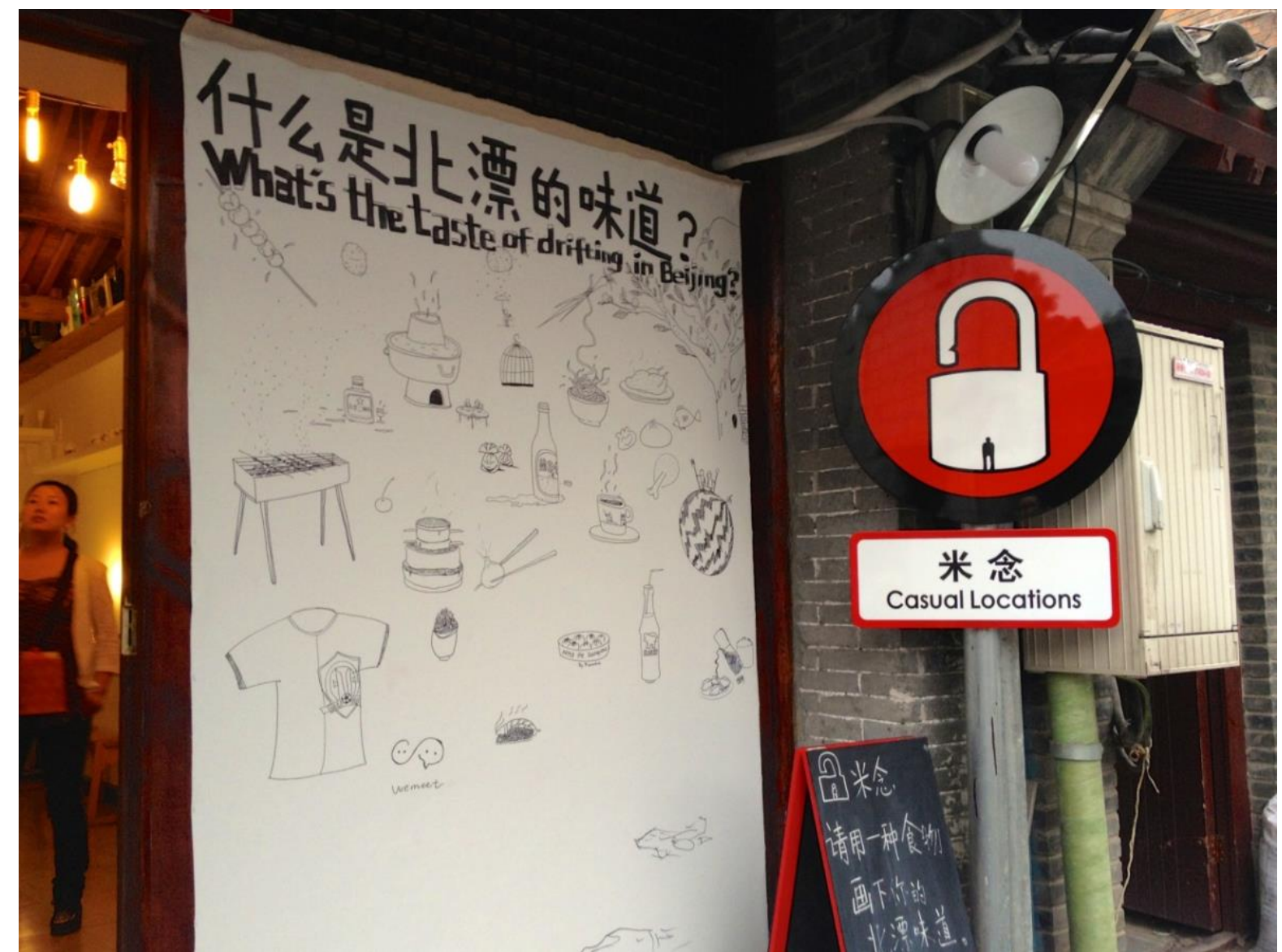

Figure 1 Casual Locations Studio's art and food project in a temporary space during Beijing Design Week Source: photo taken by the author

The collaboration between Beijing Design Week and the Dashilar area is seen as a win-win relationship by staff who are in charge of the regeneration project. On the one hand, given the central location of Dashilar and its proximity to some of the major tourist attractions in Beijing (Tiananmen Square and Qianmen), staging part of Beijing Design Week in this area helps promote the event, attracting more audiences and visitors to the temporary exhibitions, forums, and shops, and strengthening the potential impact of the event. On the other hand, being involved in and hosting part of Beijing Design Week provides the Dashilar area with an opportunity to test and demonstrate how the design industry and creative and cultural uses in general may change the look and feel of the area, making the case for a creative/cultureled regeneration of the neighbourhood (interviews with regeneration project staff, S- 1 and S3). The name of the section of Beijing Design Week that is staged at Dashilar clearly reflects this second aspect of the collaboration: 'Dashilar New Landscape' (Dashilar 2014). 
Zhang, A.Y. 2021. Address urban regeneration challenge with temporary creative uses: the case of Beijing's Dashilar area. In Andres, L., and Zhang, A.Y. (eds.) Transforming Cities through Temporary Urbanism: A Comparative International Overview. Springer.

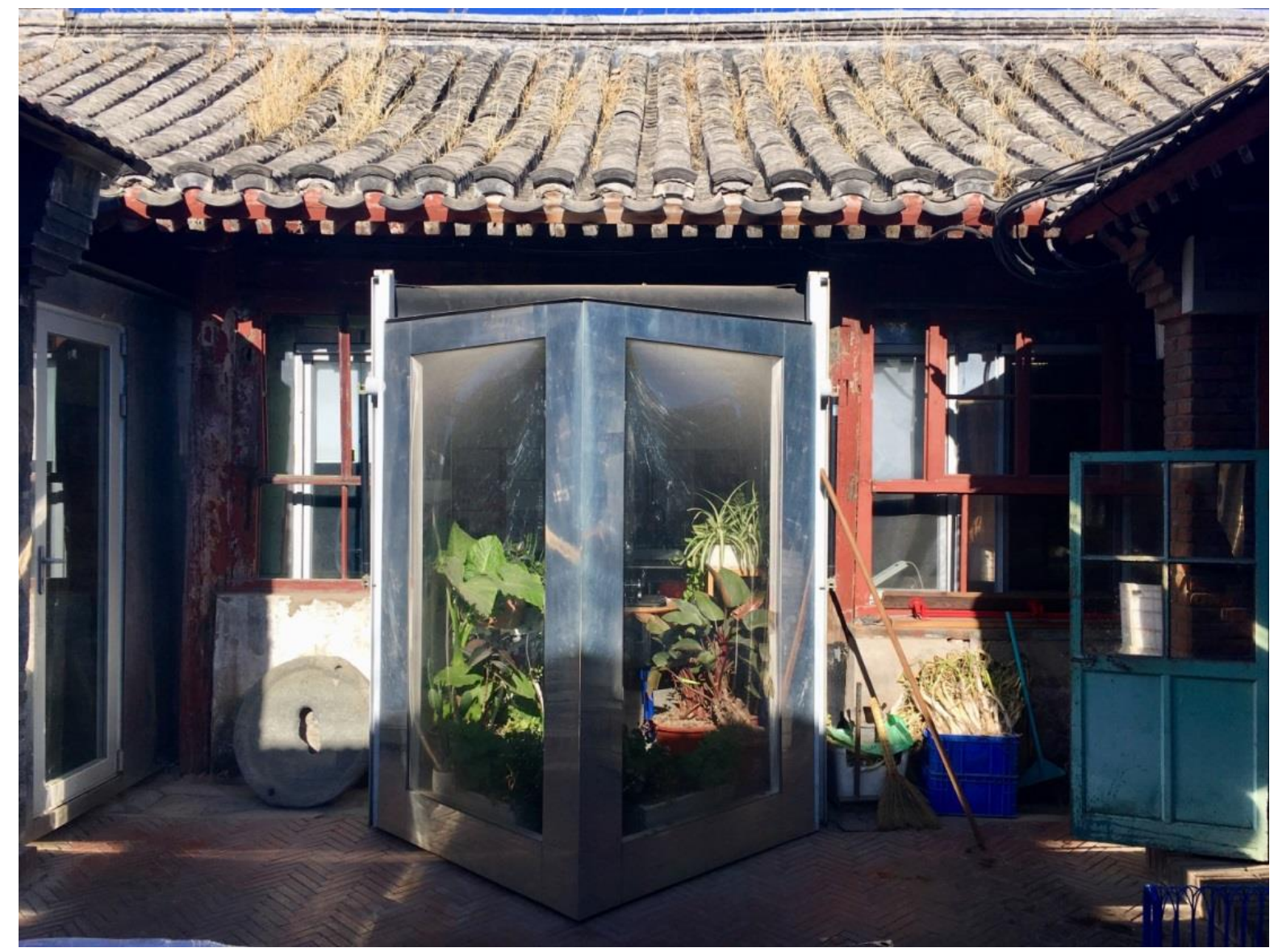

Figure 2 Courtyard House Plugin modular system created by People's Architecture Office 2

Source: photo taken by the author

As the name 'Dashilar New Landscape' indicates, the landscape created during and as a result of Beijing Design Week embodies the vision of the district government and regeneration project staff for the Dashilar area. Similar to those demonstrated in existing studies (Colomb 2012; Schaller and Guinand 2018), temporary creative uses in this case are drawn on to provide opportunities for potential new land and property users, tenants and investors to witness and experience an alternative version of the Dashilar neighbourhood (Zhang 2018). This experience is believed to be able to help change their perceptions of the area and stimulate their interests in realising this 'new landscape' of Dashilar, not only temporarily during Beijing Design Week but also more permanently in the long term, namely regenerating the area through creative and cultural uses (interviews with regeneration project staff, S-1 and S-2). In addition, and in particular to the Chinese context, staging temporary creative uses in the Dashilar area as part of the Beijing Design Week signals the district government's approval of, interest in, and support to adapt vacant courtyard houses in the area for creative and cultural uses, which offers the assurance that many individuals and businesses in the creative and cultural sectors need before making their decisions about location choices (interviews with regeneration project staff S-1 and S-3).

\footnotetext{
${ }^{2}$ For more information, see: https://www.dezeen.com/2014/10/17/courtyard-house-plugin-peoplesarchitecture-office-repurpose-beijing-residencies/
} 
Zhang, A.Y. 2021. Address urban regeneration challenge with temporary creative uses: the case of Beijing's Dashilar area. In Andres, L., and Zhang, A.Y. (eds.) Transforming Cities through Temporary Urbanism: A Comparative International Overview. Springer.

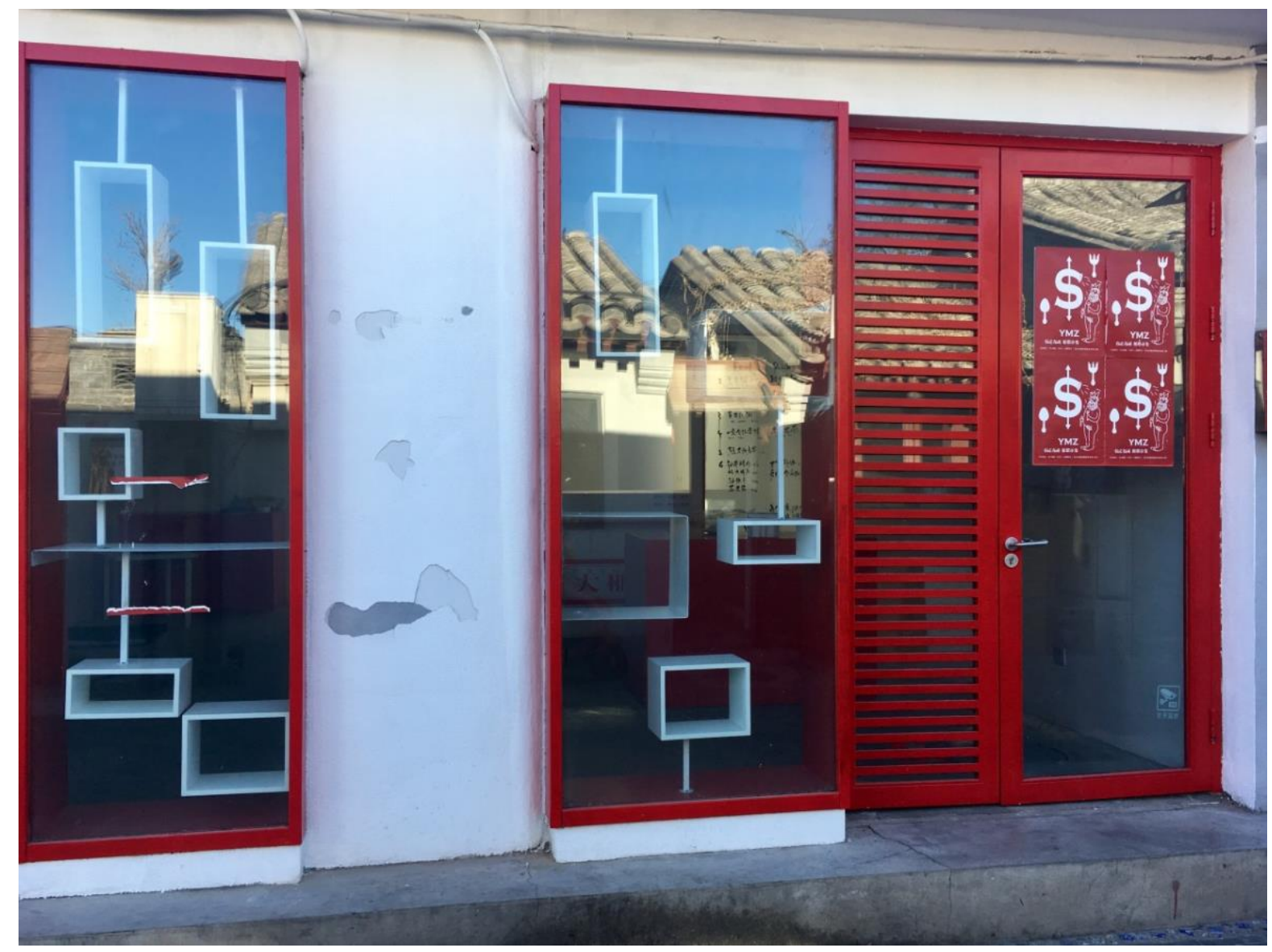

Figure 3 Vacant space after being used for temporary exhibition and shop during Beijing Design Week Source: photo taken by the author

More importantly for the regeneration project in the Dashilar area, engaging with temporary creative uses works as a strategy to both carry out regeneration in the area and meet the requirements and restrictions imposed on regeneration by the relevant planning regulations. First, the image of the Dashilar area created through temporary creative uses during Beijing Design Week is a particular one. It shows not only that the neighbourhood can be suitable for the location of creative and cultural industries and uses, but also that individuals and businesses in the creative and cultural sectors can utilise vacant courtyard houses in the Dashilar area while existing side-by-side with residential uses that remain there. Making this image of co-existence attractive and desirable is particularly important for the regeneration project. Given the municipal government's restrictions on the scale and speed of regeneration in conservation areas, pushing for regenerating and reusing already vacant courtyard houses on a small scale is one of the few options left for the district government to generate the necessary revenue to finance further regeneration. To be able to effectively carry out regeneration on a courtyard-by-courtyard or house-by-house basis within an environment that is still mainly characterised as residential and relatively run-down is thus seen as crucial for the regeneration project in the Dashilar area. The buzz and atmosphere created through hosting temporary creative uses during Beijing Design Week paint an image of happy and exciting co-existence of creative uses and local residents in the Dashilar area (interview with regeneration project staff, S-4). This image helps increase the willingness of some individuals and businesses in the creative and cultural sectors to choose vacant courtyard houses in the 
Zhang, A.Y. 2021. Address urban regeneration challenge with temporary creative uses: the case of Beijing's Dashilar area. In Andres, L., and Zhang, A.Y. (eds.) Transforming Cities through Temporary Urbanism: A Comparative International Overview. Springer.

area as their locations while having local residents as their neighbours, which in turn facilitates small-scale regeneration in the area.

Secondly, temporary creative uses are perceived as being able to attract new land and property users and tenants that are desired by the regeneration project of the Dashilar area, namely individuals and businesses in the creative and cultural sectors. This group is viewed as the most suitable to be the new members of the area in view of the requirements on historical conservation and restoration there. As mentioned above, regeneration of conservation areas is required to preserve and restore the historical features and aesthetic of the built environment, which can add to the cost and thus financial burden that the district government has to shoulder. It is thought that individuals and businesses in the creative and cultural sectors, due to their professions, would be interested in preserving and restoring the historical features and aesthetic of courtyard houses through careful renovation on their own (interviews with regeneration project staff, $\mathrm{S}-1$ and $\mathrm{S}-2$ ). Based on this understanding, the district government is able to demand that new users and tenants of courtyard houses should carry out renovations that meet the conservation requirements without fear of deterring too many potential new users and tenants. In this way, the district government are able to shift the execution of conservation and restoration that are parts of the regeneration of the Dashilar area and the associated costs to those who are interested in being part of a 'new landscape' of the neighbourhood.

And lastly, temporary creative uses, together with long-term cultural and creative uses attracted to the area, have assisted the regeneration project to get close to the target set on reducing population density in the Dashilar area. Although temporary creative uses in Dashilar take place in already vacant properties instead of directly displacing local residents, they arguably also work to pressure or 'encourage' (interview with regeneration project staff, S-4) local residents to move out of the area by changing the uses of spaces and the visitors to the alleys (Luo 2015). Regeneration project staff interviewed for this study (S-1 and S-2) indicate that about $30-40 \%$ of the total population of Yangmeizhu xiejie, where the majority of temporary creative uses and long-term cultural and creative uses currently concentrate in the Dashilar area, had been displaced by 2019 . This number is close to the overall $41 \%$ displacement target set for the 25 conservation areas as a whole, which demonstrates to some extent the effectiveness of the strategy of engaging with temporary creative uses for carrying out regeneration in the Dashilar area. However, regeneration project staff interviewed for this study were clearly not satisfied with this result, largely due to the underutilisation of the spaces that are emptied in the regeneration process: only about $20 \%$ of vacant spaces on Yangmeizhu xiejie had been turned into rent-paying uses by early 2019.

\section{Discussion and conclusion}

The outcome given at the end of the last section shows that while temporary creative uses and the resulting culture-led regeneration can play a role in pressuring local residents to move out of the area and open up more spaces for creative and cultural uses, they fail to demonstrate the expected effectiveness in drawing individuals and businesses in the creative and cultural sectors to the Dashilar area. This outcome opens up two interesting avenues for further inquiries. On the one hand, the relatively small scale of new uses in the Dashilar area 
Zhang, A.Y. 2021. Address urban regeneration challenge with temporary creative uses: the case of Beijing's Dashilar area. In Andres, L., and Zhang, A.Y. (eds.) Transforming Cities through Temporary Urbanism: A Comparative International Overview. Springer.

suggests that there is still a certain level of stability for local residents. This relative stability also opens up the possibility of exploring the co-existence of creative and cultural uses and local residents in the Dashilar area that is based on and characterised by sharing, caring for, and building the space and community together rather than one that aims at replacing one group (local residents) with the other (creative and cultural uses). On the other hand, the failure of this regeneration approach to meet the district government's expectation of it to effectively attract the desired new land and property users and tenants to the Dashilar area indicates that more questions need to be asked in future research on the factors that can potentially affect the outcome of certain regeneration approaches. The case of the Dashilar area shows that presenting a potential alternative image of the area, even when coupled with signalled support from the district government, is not sufficient to induce strong interests in the area from individuals and businesses in the creative and cultural sectors. It is thus necessary to examine further the influences of other factors that are also at play.

Following from the latter point in the previous paragraph and as indicated in the introduction, I would like to end this chapter with a brief discussion of the potential diversity of temporary urbanism practices, even within those that are engaged by city governments for regeneration purposes. In comparison with cases examined in existing literature (Colomb 2012; Schaller and Guinand 2018), the case of the Dashilar area is similar in that temporary creative uses are enlisted to construct an alternative, arguably more attractive, image of the area in order to induce interests of and bring in new land and property users and tenants, eventually achieving the regeneration purpose. However, within this similarity, there is also a difference between these cases and the case of the Dashilar area. For most cases examined in the existing literature, the construction of an alternative image of the space in question through temporary creative uses is less about attracting further creative uses per se but more about bringing new uses to vacant spaces in general. In contrast, the approach of engaging with temporary creative uses for regeneration in the Dashilar area is specifically intended to attract one particular group, whose members are seen as being able to help the district government both meet the requirements and restrictions on regeneration and achieve regeneration in the area.

Moreover, while cases examined in some Western cities show that temporary creative uses are employed to address the problem of vacant land and property (Andres 2013; Colomb 2012; O'Callaghan and Lawtown 2015), the case of Dashilar demonstrates how temporary creative uses are drawn on to not only facilitate reuse of vacant properties but also actively produce vacancies. The focus of the regeneration project in the Dashilar area is two-fold: one is to change the use and look of the area (Zhang 2018) and the other is to meet the target set by the municipal government on reducing population density. As the current outcome of the regeneration project in the Dashilar area, shown in the previous section, indicates, temporary creative uses may be less effective in delivering the former aspect of the focus but are arguably powerful in helping the regeneration project achieve the latter aspect. This finding suggests that, even with the relatively small amount of new uses presented in the area, the environment created by and message conveyed by temporary creative uses can cause pressure on local residents and lead to their displacement. It is thus necessary to be alert to the various uses of temporary urbanism practices by city governments and investigate closely the intentions of such practices. 
Zhang, A.Y. 2021. Address urban regeneration challenge with temporary creative uses: the case of Beijing's Dashilar area. In Andres, L., and Zhang, A.Y. (eds.) Transforming Cities through Temporary Urbanism: A Comparative International Overview. Springer.

In summary, the case of the Dashilar area shows how a local district government in Beijing employs temporary creative uses to carry out regeneration while also meeting the requirements and restrictions imposed on regeneration in the area by the relevant planning regulations. As discussed above, there are clear differences between this case and some cases examined in the existing literature in terms of the reasons for selecting the strategy of engaging with temporary creative uses, the purposes of introducing temporary creative uses to the area, and the effects of temporary creative uses. These differences highlight not only the potential diversity of temporary urbanism practices but also the importance to contextualise the choice and use of such practices in specific cases.

\section{Funding}

This research is funded by British Academy/Leverhumle Small Resarch Grant (SRG\170228). 
Zhang, A.Y. 2021. Address urban regeneration challenge with temporary creative uses: the case of Beijing's Dashilar area. In Andres, L., and Zhang, A.Y. (eds.) Transforming Cities through Temporary Urbanism: A Comparative International Overview. Springer.

\section{References}

Andres L (2013) Differential spaces, power hierarchy and collaborative planning: a critique of the role of temporary uses in shaping and making places. Urban Studies 50(4):759-775 Beijing Municipal Commission of Planning and Natural Resources (BMCPNR) (2002a) Conservation planning for the 25 historic and cultural conservation areas in Beijing Old City (Beijing jiucheng 25 pian lishi wenhua baohuqu baohu guihua). http://wwj.beijing.gov.cn/bjww/362690/362731/gh/622510/index.html. Accessed 16 March 2017

Beijing Municipal Commission of Planning and Natural Resources (BMCPNR) (2002b) Conservation planning for the famous historic and cultural city of Beijing (Beijing lishi wenhua mingcheng baohu guihua). http://pkulaw.cn/CLI.14.39085. Accessed 22 March 2019

Beijing Municipal Commission of Planning and Natural Resources (BMCPNR) (2011) Conservation and construction planning for the famous historic and cultural city during the "twelfth five-year" period in Beijing (Beijing shi "shi'er wu" shiqi lishi wenhua mingcheng baohu jianshe guihua). http://ghzrzyw.beijing.gov.cn/zhengwuxinxi/ghcg/zxgh/201912/t20191213_1165428.html. Accessed 21 March 2019

Beijing Municipal Government (BMG) (1999) Plan for conservation and control scope for the historic and cultural conservation areas in Beijing Old City (Beijing jiucheng lishi wenhua baohuqu baohu he kongzhi fanwei guihua). http://wwj.beijing.gov.cn/bjww/362690/362731/gh/622507/index.html. Accessed 16 March 2017

Colomb C (2012) Pushing the urban frontier: temporary uses of space, city marketing, and the creative city discourse in 2000s Berlin. Journal of Urban Affairs 34(2):131-152

Dashilar (2014) Dashilar new landscape (Dashilar xin jiejing). http://dashilar.beijing99.cn/index.htm\#A!/A/A2_XJJ.html. Accessed 20 April 2020 Ferreri M (2015) The seduction of temporary urbanism. Ephemera 15(1):181-191 Harris E (2015) Navigating pop-up geographies: Urban space-times of flexibility, interstitiality and immersion. Geography Compass 9(11):592-603

He S, Wu F (2005) Property-led redevelopment in post-reform China: A case study of Xintiandi redevelopment project in Shanghai. Journal of Urban Affairs 27(1):1-23

Luo T (2015) Dashilar, the awakening of Old Beijing (Dashilar, suxing zhong de Beijing lao chengqu). The New York Times (Chinese website). https://cn.nytimes.com/culture/20150603/tc03dashilar/. Accessed 26 March 2019

O'Callaghan C, Lawton P (2015) Temporary solutions? Vacant space policy and strategies for re-use in Dublin. Irish Geography 48(1):69-87

Schaller S, Guinand S (2018) Pop-up landscapes: A new trigger to push up land value? Urban Geography 39(1):54-74

Shin HB (2009) Residential redevelopment and the entrepreneurial local state: The implications of Beijing's shifting emphasis on urban redevelopment policies. Urban Studies 46(13):2815-2839

Shin HB (2010) Urban conservation and revalorisation of dilapidated historic quarters: The case of Nanluoguxiang in Beijing. Cities 27:S43-S54.

Zhang, AY (2018) Pop-up urbanism: Selling Old Beijing to the creative class. In: Jayne M (ed) Chinese urbanism: Critical perspectives. Routledge, London, pp 137-148 
Zhang, A.Y. 2021. Address urban regeneration challenge with temporary creative uses: the case of Beijing's Dashilar area. In Andres, L., and Zhang, A.Y. (eds.) Transforming Cities through Temporary Urbanism: A Comparative International Overview. Springer. 